\title{
Anti-vascular endothelial growth factor antibody and nimustine as combined therapy: Effects on tumor growth and angiogenesis in human glioblastoma xenografts ${ }^{1}$
}

\author{
Shingo Takano, ${ }^{2}$ Koji Tsuboi, Akira Matsumura, and Tadao Nose \\ Department of Neurosurgery, Institute of Clinical Medicine, University of Tsukuba, Tsukuba, \\ Ibaraki 305-8575, Japan
}

\begin{abstract}
We evaluated the effectiveness of vascular endothelial growth factor (VEGF) blockade alone and in combination with 1-(4-amino-2-methyl-5-pyrimidinyl)methyl-3-(2-chloroethyl)-3-nitrosourea (ACNU, nimustine), a cytotoxic agent commonly used in the treatment of malignant gliomas, to eradicate tumors of human glioblastoma cell lines implanted in SCID (severe combined immunodeficiency) mice. ACNU, but not cisplatin and etoposide, elevated VEGF expression in a glioma cell line in vitro. VEGF antibody alone inhibited glioma growth in vivo as a result of angiogenesis inhibition. The combination with ACNU resulted in an additive effect for inhibition of glioma growth. ACNU also induced VEGF up-regulation in glioma tissues, which was decreased with VEGF antibody treatment. One of the mechanisms of the additive effect of the VEGF antibody and ACNU combination is the blockade of VEGF up-
\end{abstract}

Received 29 January 2002; accepted 27 June 2002.

${ }^{1}$ This study was supported by a Grant-in-Aid for Scientific Research from the Japanese Ministry of Education, Science, and Culture, and by a grant provided by the Ichiro Kanehara Foundation.

${ }^{2}$ Address correspondence and reprint requests to Shingo Takano, M.D., Ph.D., Department of Neurosurgery, Institute of Clinical Medicine, University of Tsukuba, 1-1-1 Tennoudai, Ibaraki 305-8575, Japan.

${ }^{3}$ Abbreviations used are as follows: ACNU, 1-(4-amino-2-methyl-5pyrimidinyl)methyl-3-(2-chloroethyl)-3-nitrosourea, nimustine; RT-PCR, reverse transcriptase-polymerase chain reaction; ELISA, enzyme-linked immunosorbent assay; PBS, phosphate-buffered saline; SCID, severe combined immunodeficiency; VEGF, vascular endothelial growth factor. regulation induced by ACNU. As such, the combination of antiangiogenic therapy with conventional therapy is promising for glioma treatment in the future. Neuro-Oncology 5, 1-7, 2003 (Posted to Neuro-Oncology [serial online], Doc. 02-007, December 4, 2002. URL http://neurooncology.mc.duke.edu)

\footnotetext{
A ngiogenesis, the growth of new blood vessels from those pre-existing in tissue, is crucial to glioma growth (Zagzag, 1995). Glioblastoma is the most common and most malignant brain tumor in humans, and the feature that distinguishes glioblastomas from benign astrocytomas is the presence of vascular endothelial proliferation. In fact, glioblastoma is one of the most richly neovascularized solid tumors in terms of vasoproliferation, endothelial hyperplasia, and endothelial cytology (Brem et al., 1972). Ultrastructurally, the microvasculature of glioblastomas is different from that of benign astrocytomas and normal brains in terms of both vascular permeability and endothelial proliferative potential (Takano et al., 1991a, 1991b). Therefore, antiangiogenic therapy represents a new, promising therapeutic modality for glioblastomas (Kirsch et al., 1998; Lund et al., 1998).

Various angiogenic factors have been described in glioma angiogenesis (Jensen, 1998). Among them, VEGF $^{3}$ has been shown to be the most potent angiogenic factor in human gliomas (Lund et al., 1998). VEGF concentrations in gliomas correlate significantly with vascularity, and conditioned media of glioma cells containing high VEGF concentrations have been found to induce endothelial cell migration (Takano et al., 1996).
} 
Recognition of VEGF as one of the primary stimulants of angiogenesis has led to the development of neutralizing antibodies (Asano et al., 1998; Kim et al., 1993), soluble receptor constructs (Kendall and Thomas, 1993; Millauer et al., 1996), and antisense strategies (Cheng et al., 1996) that either block angiogenesis or suppress tumor growth by interfering with VEGF signaling. Immunoneutralizing antibodies to VEGF suppresses the growth of solid tumors, including malignant gliomas (Bernsen et al., 1998; Kim et al., 1993; Yuan et al., 1996). However, many tumor cells survive with this treatment, during which tumor growth is not blocked completely (Bernsen et al., 1998).

The synergy of antiangiogenic therapy combined with conventional therapy, ionizing radiation, and chemotherapy has been demonstrated. TNP-470, a synthetic analog of fumagillin, has been shown to significantly potentiate the effects of cyclophosphamide (Teicher et al., 1994) and ionizing radiation (Lund et al., 2000). VEGF neutralizing antibody in combination with doxorubicin (Borgstrom et al., 1999) and ionizing radiation (Gorski et al., 1999) results in significant tumor regression. Angiostatin, a proteolytic fragment of plasminogen, in combination with ionizing radiation potentiates an antitumor interaction (Mauceri et al., 1998). Although ACNU is commonly used for malignant gliomas, its antitumor effect is limited (Takakura et al., 1986; Yoshida et al., 1994). In the present study, we evaluated the effectiveness of VEGF blockade alone and in combination with ACNU, a cytotoxic agent commonly used in the treatment of malignant gliomas, in eradicating tumors of human glioblastoma cell lines implanted in SCID mice.

\section{Materials and Methods}

\section{Human Glioma Cell Lines and Culture Conditions}

Human glioma cell lines U-87 MG and U-251 MG were obtained from the American Type Culture Collection (Rockville, MD.). Cells were maintained in Eagle's minimum essential medium supplemented with $10 \%$ fetal calf serum in a humidified atmosphere containing $5 \% \mathrm{CO}_{2}$ at $37^{\circ} \mathrm{C}$.

\section{Chemotherapeutic Agent Treatment In Vitro}

We plated $5 \times 10^{4}$ glioma cells into a 6 -well plate. After the cells had been incubated for $24 \mathrm{~h}$ in Eagle's minimum essential medium with $10 \%$ fetal calf serum, the medium was changed to Eagle's minimum essential medium with $10 \%$ fetal calf serum containing various concentrations of ACNU, etoposide, and cisplatin $(1,5,10,50 \mu \mathrm{M})$. After a 48-h incubation, total RNA and the conditioned medium were harvested and used for RT-PCR analysis and VEGF ELISA. The experiment was repeated twice in quadruplicate for each concentration.

\section{U-87 MG SCID Mouse Subcutaneous Model}

After implantation of $1 \times 10^{5} \mathrm{U}-87 \mathrm{MG}$ cells in the flank of a 6-week-old male SCID mouse (Japan Clea, Tokyo, Japan), U-87 MG tumor tissue fragments were removed and then reimplanted in the flank of another SCID mouse. Harvested tumor fragments $1 \mathrm{~mm}^{3}$ in size were immediately implanted in the flank of a third SCID mouse. ACNU treatment was begun 16 days after implantation, when the s.c. tumor reached $5 \mathrm{~mm}$ in size. ACNU $(20 \mathrm{mg} / \mathrm{kg})$ was injected intraperitoneally 15, 19, and 23 days after implantation. VEGF antibody at a dose of $100 \mu \mathrm{g} /$ mouse was injected intraperitoneally on days 15, 19, 23, 26, 30, 33, 37, and 40. The VEGF antibody used was the immunoneutralizing monoclonal antibody to human VEGF and inhibited the growth of human umbilical vein endothelial cells induced by $\mathrm{VEGF}_{121}$ and the binding of ${ }^{125} \mathrm{I}$-labeled VEGF $_{121}$ to human umbilical vein endothelial cells (Asano et al., 1998). This antibody has revealed its antitumor activity against 27 human tumor cell lines transplanted in nude mice (Asano et al., 1999). Two parallel series of experiments were performed. One set of the experiments was used for tumor volume calculation and tumor tissue collection. Another set of the experiments was used to measure survival rate. In each experiment, the mice were divided into 4 groups $(n=6)$ and given the following: VEGF antibody, ACNU, VEGF antibody plus ACNU, and saline. The size of the s.c. tumors was measured by caliper. Tumor volume $(T V)$ was calculated using the formula: $T V=W^{2} \times L$ / 2 (with $W$ being the shortest diameter and $L$ being the longest diameter). Forty days after implantation, the tumor tissue was removed. Part of the tissue was immediately fixed in $10 \%$ phosphate-buffered formalin for $48 \mathrm{~h}$, paraffin embedded, and then used for routine pathologic diagnosis and immunohistochemistry. Other parts of tissues were immediately frozen with liquid nitrogen and stored at $-70^{\circ} \mathrm{C}$. Institutional guidelines for animal welfare and experimental conduct were followed.

\section{U-87 MG SCID Mouse Intracranial Model}

Using a Hamilton syringe and a 26 gauge needle, we injected 16 SCID mice in the right frontal lobe at a depth of $2 \mathrm{~mm}$ with $1 \times 10^{6} \mathrm{U}-87 \mathrm{MG}$ cells in $10 \mu \mathrm{l}$ PBS. The animals were divided equally into 4 groups $(n=4)$ : control group, ACNU group, VEGF antibody group, and ACNU plus VEGF antibody group. ACNU $(20 \mathrm{mg} / \mathrm{kg})$ was injected intraperitoneally 4, 7, and 10 days after the implantation. VEGF antibody at a dose of $100 \mu \mathrm{g} / \mathrm{mouse}$ was injected intraperitoneally on days 4, 7, 10, 13, 16, 19, 22 , and 25. Statistical significance of survival between different groups was assessed using log-rank analysis of Kaplan-Meier survival curves.

\section{RNA Isolation and RT-PCR}

Total RNA was extracted from treated and control frozen tumor tissues (4 control, 4 ACNU, 4 VEGF antibody, 4 ACNU plus VEGF antibody), and glioma cell lines were treated with chemotherapeutic agents using the RNeasy Mini Kit (Qiagen GmbH, Hilden, Germany) described previously (Takano et al., 2000). Quantitative RT-PCR for VEGF and $B$-actin mRNA in glioma cells and glioma tissues has been described previously (Takano et al., 2000). We performed RT-PCR with the GeneAmp ${ }^{\text {TM }}$ RNA PCR Kit (Perkin-Elmer Cetus, Norwalk, Conn.). Briefly, $1 \mu \mathrm{g}$ of 
total RNA was reverse-transcribed by murine leukemia virus reverse transcriptase in the presence of random hexamer followed by the indicated cycles of the PCR reaction $\left(95^{\circ} \mathrm{C}\right.$ for $1 \mathrm{~min}, 55^{\circ} \mathrm{C}$ for $1 \mathrm{~min}$, and $72^{\circ} \mathrm{C}$ for $1 \mathrm{~min}$ ) in the presence of $2 \mu \mathrm{M}$ VEGF-specific primers ( 28 cycles) or in the presence of the $ß$-actin-specific primers ( 16 cycles) as a control. The VEGF primers included the reverse primer (5'-CCTGGTGAGAGATCTGGTTC-3') spanning bases 861-842 and the forward primer (5'-TCGGGCCTCCGAAACCATGA-3') spanning bases 141-160. The $B$-actin primers included the reverse primer (5'-GGAGTTGAAGGTAGTTTCGTG-3') spanning bases 2429-2409 and the forward primer (5'-CGGGAAATCGTGCGTGACAT-3') spanning bases 2107-2126. The predicted size of the amplified $ß$-actin DNA products was $214 \mathrm{bp}$. The VEGF primers were chosen because they amplified exons 3 to 8 and showed the difference between the VEGF splicing variants. PCR products of 516 bp and 648 bp corresponded with $\mathrm{VEGF}_{121}$ and $\mathrm{VEGF}_{165}$, respectively. Quantification of these RT-PCR product levels was carried out on a computer using the public domain National Institutes of Health Image program.

\section{Antibodies and Immunohistochemistry}

The DAKO LSAB Kit for mouse and rabbit primary antibody (DAKO, Glostrup, Denmark) was used (Takano et al., 1996). Tissue sections were deparaffinized and incubated with $10 \%$ normal goat serum in PBS for $20 \mathrm{~min}$. The sections were then incubated with a polyclonal antiVEGF antibody, A-20 (Santa Cruz Biotech. Inc., Santa Cruz, Calif.), at a dilution of $1 / 100(1 \mu \mathrm{g} / \mathrm{ml} \mathrm{IgG})$, a monoclonal MIB-1 antibody (Immunotech, Marseilles, France) in PBS overnight at $4^{\circ} \mathrm{C}$, and a monoclonal antimouse CD31 antibody (BD Pharmingen, San Diego, Calif. ) at a dilution of $1 / 50(10 \mu \mathrm{g} / \mathrm{ml})$ in PBS for $60 \mathrm{~min}$ at room temperature. Chromatographically purified mouse IgG and rabbit IgG $(\mathrm{DAKO})$ at the same IgG concentration were used as negative controls. Sections were incubated with biotin-conjugated goat antimouse or antirabbit immunoglobulin for $10 \mathrm{~min}$ followed by washing in PBS for 10 min. The sections were then incubated with peroxidaseconjugated streptavidin solution for $5 \mathrm{~min}$ followed by washing in PBS for $5 \mathrm{~min}$. Sections were then stained with freshly prepared aminoethylcarbazole solution for $10 \mathrm{~min}$ followed by washing for $5 \mathrm{~min}$ in tap water. Next, sections were counterstained with hematoxylin and mounted with aqueous mounting medium. The intracellular VEGF immunostaining was assessed separately for tumor and endothelial cells using a semiquantitative scale (- not detected; + moderate; ++ strong). Nuclei positive for MIB1 were determined by counting at least 1,000 tumor cells.

\section{Tumor Vascular Density}

Vascular density was scored using the vasoproliferative component of the MAGS (microscopic angiogenesis grading system) that has been used to quantify angiogenesis in a variety of tumors (Brem et al., 1972; Takano et al., 1996). The number of vessels at a $200 x$ field $\left(1.0 \mathrm{~mm}^{2}\right)$ was measured in microvessel "hot spots" (microscopic areas containing the densest collections of microvessels, as initially identified under low-power magnification) with the use of an Olympus microscope, AHBT3 (Olympus, Tokyo, Japan), on CD31-stained tissue sections. Vascular density was determined by averaging the number of vessels in the 3 most vascularized areas.

\section{Measurement of VEGF Levels in Tumor Extracts}

Tumor extracts were prepared by homogenizing tumors in a buffer (Takano et al., 1996). VEGF levels were measured in tumor extract supernatants by the Quantikine ${ }^{\mathrm{TM}}$ Human VEGF Immunoassay (DVE00; R\&D systems, Minneapolis, Minn.). VEGF levels were normalized to total extract protein concentrations, as measured by DC protein assay, and are expressed as pg VEGF / mg total extract protein.

\section{Statistical Analyses}

Vascular density, MIB-1 positivities, tumor volumes, VEGF concentration, and the densitometric value of VEGF and $ß$-actin are expressed as mean \pm SD. Statistically significant differences between the groups were determined using a one-way analysis of variance and the Tukey test. All $P$ values are 2 -sided; values are considered statistically significant for $P<.05$.

\section{Results}

\section{ACNU Treatment Up Regulates VEGF Expression In Vitro}

ACNU treatment ( 5 and $10 \mu \mathrm{M})$ for 48 h caused an up regulation of VEGF mRNA expression of U-87 MG glioma cells in vitro (Fig. 1). At a higher dose of $50 \mu \mathrm{M}$, up-regulation of VEGF mRNA expression was unremarkable. The $50-\mu \mathrm{M}$ dose of ACNU has a weak growth

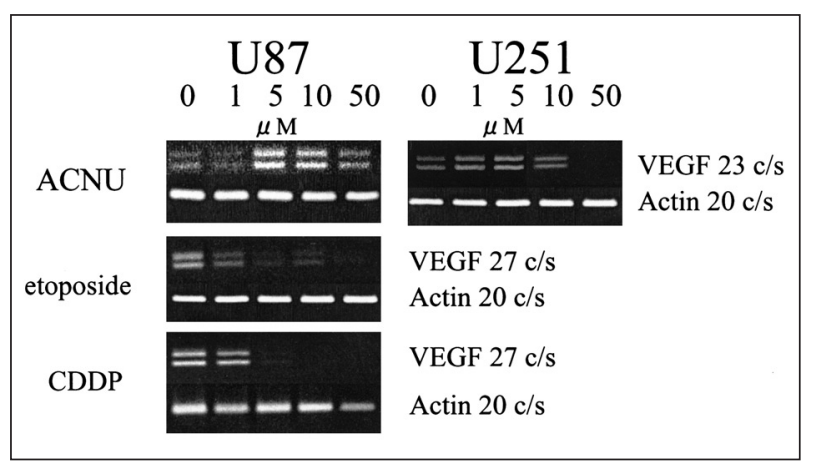

Fig. 1. RT-PCR analysis of VEGF mRNA expression in U-87 MG cells treated with $A C N U$, etoposide, and cisplatin. ACNU up-regulates VEGF expression of U-87 MG cells in vitro. U-87 MG $\left(5 \times 10^{4}\right)$ cells were treated with $A C N U$, etoposide, and cisplatin. Total RNA was harvested, and VEGF mRNA expression was evaluated by RT-PCR analysis. ACNU 5 and $10 \mu \mathrm{M}$ up-regulated VEGF mRNA expression. The effect of ACNU on U-251 MG cells was equivocal. Abbreviations: CDDP, cisplatin; c/s, cycles. 
inhibitory effect for this cell line (data not shown). Therefore, at this dose, VEGF expression could be slightly decreased instead of being up regulated. By contrast, etoposide (5 and $10 \mu \mathrm{M})$ and cisplatin $(5$ and $10 \mu \mathrm{M})$ under the nontoxic doses did not induce VEGF mRNA expression (Fig. 1). In one experiment, VEGF concentration in the conditioned medium with ACNU treatment for $48 \mathrm{~h}$ was measured by ELISA. Up-regulation of VEGF concentration with ACNU treatment was observed: $2,582 \mathrm{pg} / \mathrm{ml}$ in control, $3,809 \mathrm{pg} / \mathrm{ml}$ in $5-\mu \mathrm{M} \mathrm{ACNU}$, and $3,756 \mathrm{pg} / \mathrm{ml}$ in 10- $\mu \mathrm{M}$ ACNU. Up-regulation of VEGF mRNA expression of U-251 MG glioma cells was equivocal (Fig. 1).

\section{Combined Effect of ACNU and VEGF Antibody Treatment on U-87 MG Subcutaneous Growth and Survival}

The tumor volumes as measured for each group are shown in Fig. 2A. ACNU alone and VEGF antibody alone significantly inhibited tumor growth compared with the control after day 29. Combination therapy with ACNU and VEGF antibody significantly inhibited tumor growth, even after 20 days (Fig. 2A). On day 40 the tumor volumes in each group were 4,153.4 $\pm 1,401.8 \mathrm{~mm}^{3}$ (control group), $1,494.0 \pm 679.0 \mathrm{~mm}^{3}$ (ACNU group, $P=0.019$ ), $1,223.6 \pm 453.6 \mathrm{~mm}^{3}$ (VEGF antibody group, $P=$ 0.0016 ), and $220.0 \pm 301.2 \mathrm{~mm}^{3}$ (ACNU plus VEGF antibody group, $P=0.0002$ ). We plotted the growth data for each mouse in each group, computed the slope of the growth curve in each mouse, and compared the slopes between treatment groups. The values of the slopes (mean $\pm \mathrm{SD}$ ) were $2.50 \pm 0.11$ in control, $2.16 \pm 0.07$ in ACNU, $2.04 \pm 0.39$ in VEGF antibody, and $1.71 \pm 0.01$ in ACNU plus VEGF antibody. The slopes of growth were significantly lower in the ACNU alone, VEGF antibody alone, and combined therapy groups compared with control $(P<0.05$, Fig. 2B). The median survival times after

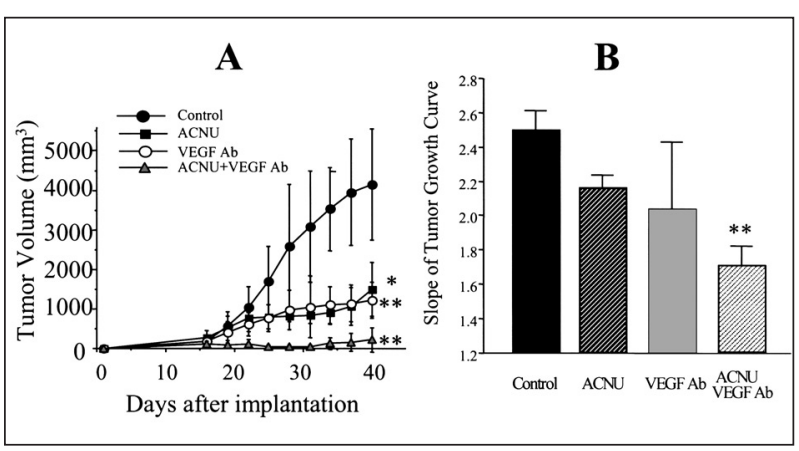

Fig. 2. Additive effect of ACNU combined with VEGF antibody treatment on U-87 MG s.c. growth. Intraperitoneal injections of ACNU at $20 \mathrm{mg} / \mathrm{kg}$ (days 15, 19, 23) and VEGF antibody at $100 \mu \mathrm{g} / \mathrm{mouse}$ (every 3 days, days $15-40$, total 8 times) were given. A. Tumor volume measured in each group $(n=6) ;{ }^{*} P<0.05,{ }^{*} P<0.01$ compared with control. B. The values of slope of tumor growth. The slope of the growth curve for each mouse in each group was measured and these were compared between groups. The value of the slope was significantly lower in the combined therapy group compared with the control and ACNU groups $(P<0.01)$. Error bars, \pm SD .

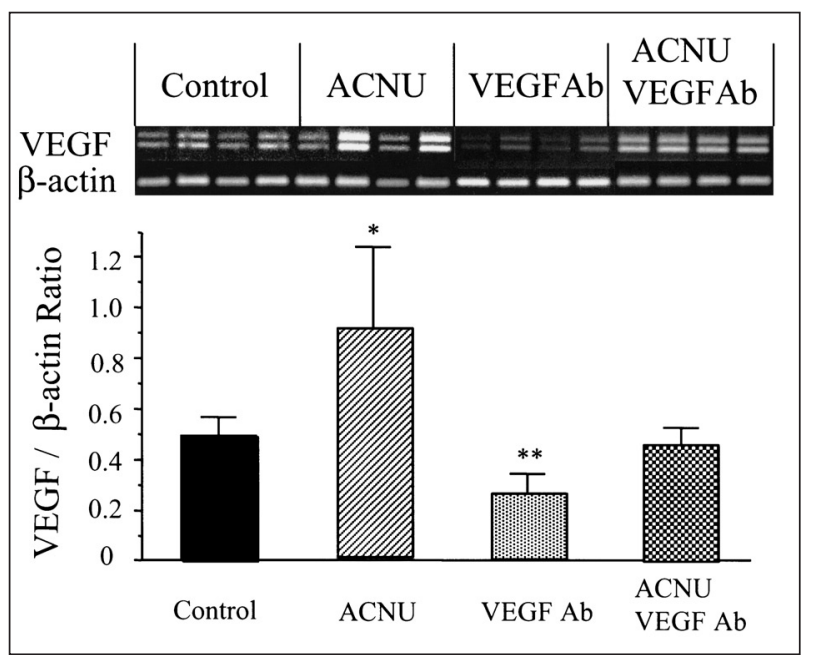

Fig. 3. U-87 MG tissue VEGF mRNA expression with ACNU / VEGF antibody treatment. VEGF expression was measured by RT-PCR analysis (A) and densitometric analysis (B). ACNU up-regulated VEGF expression, with the up-regulation being decreased by the presence of VEGF antibody. Error bars, \pm SD.

implantation in each group were $7.5 \pm 0.3$ weeks (control group), $11.5 \pm 0.5$ weeks (ACNU group), $10.5 \pm 0.5$ weeks (VEGF antibody group), and $15.8 \pm 0.3$ weeks (ACNU plus VEGF antibody group). Combination therapy significantly prolonged U-87 MG-bearing mouse survival $(P=0.007$, Mantel-Cox log-rank test).

\section{Histopathology and VEGF Expression with the ACNU and VEGF Antibody Combination Treatment}

VEGF expression of tumor tissues was evaluated by RTPCR for mRNA, by ELISA for protein concentration, and by immunohistochemistry for protein localization. VEGF mRNA expression measured by RT-PCR is shown in Fig. 3. Densitometric analysis revealed that the relative value of VEGF/ $B$-actin is $0.49 \pm 0.07$ in the control group, 0.91 \pm 0.32 in the ACNU-treated group, $0.26 \pm 0.08$ in the VEGF antibody treatment group, and $0.46 \pm 0.07$ in the ACNU plus VEGF antibody treatment group. VEGF mRNA expression was up-regulated in the ACNU-treated group compared with the control group. ACNU combined with VEGF antibody treatment decreased the up regulation of VEGF mRNA expression (Fig. 3).

VEGF protein concentration as measured by ELISA is shown in Fig. 4. VEGF concentration in the tissue of each group $(n=6$, mean $\pm \mathrm{SD}, \mathrm{pg} / \mathrm{mg}$ protein) was $891.4 \pm$ 238.0 in the control group, $3,020.9 \pm 826.3$ in the ACNU group, 4,442.2 $\pm 1,200.0$ in the VEGF antibody group, and $2,234.5 \pm 252.4$ in the ACNU plus VEGF antibody group. VEGF concentrations in the ACNU group significantly $(P<0.01)$ increased compared with the control group. VEGF concentrations in the VEGF antibody group also significantly $(P<0.01)$ increased compared with the control group, presumably due to detection of the VEGF antigen-antibody complex, the presence of which was decreased in combination with ACNU. 


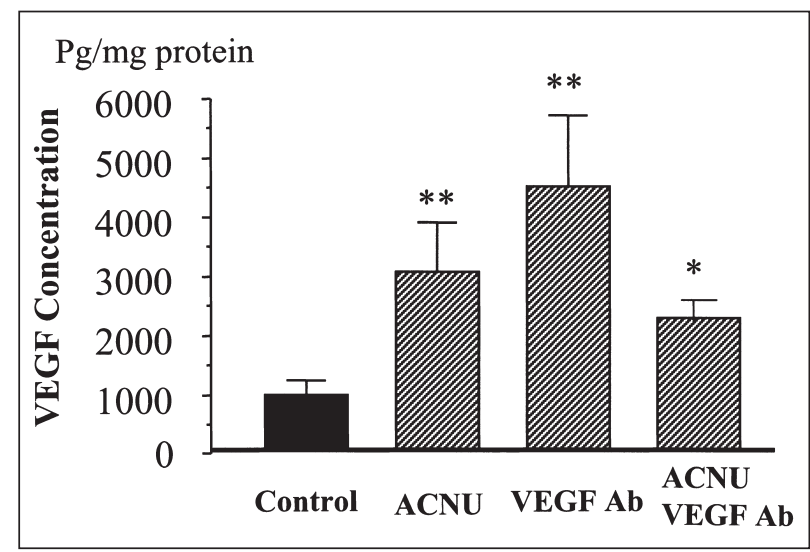

Fig. 4. VEGF concentration in U-87 MG tissue with ACNU / VEGF antibody treatment. VEGF concentration was measured by ELISA. $A C N U$ increased VEGF protein concentration, with the increase being decreased by the presence of VEGF antibody; ${ }^{*} P<0.05$, ${ }^{*} P<0.01$ compared with control. Error bars, \pm SD .

With VEGF immunohistochemistry, all 6 specimens in the control group stained strongly for VEGF $(++)$. VEGF antibody treatment (all 6 specimens (-) for VEGF) and ACNU plus VEGF antibody treatment (all 6 specimens (-) for VEGF), but not ACNU treatment (3 specimens (-) and 3 specimens $(+)$ for VEGF), dramatically decreased VEGF protein expression of the tumor cell itself (Fig. 5).

MIB-1 positivities and vessel densities in each group are shown in Table 1. The combination therapy of ACNU with VEGF antibody demonstrated a stronger effect com-

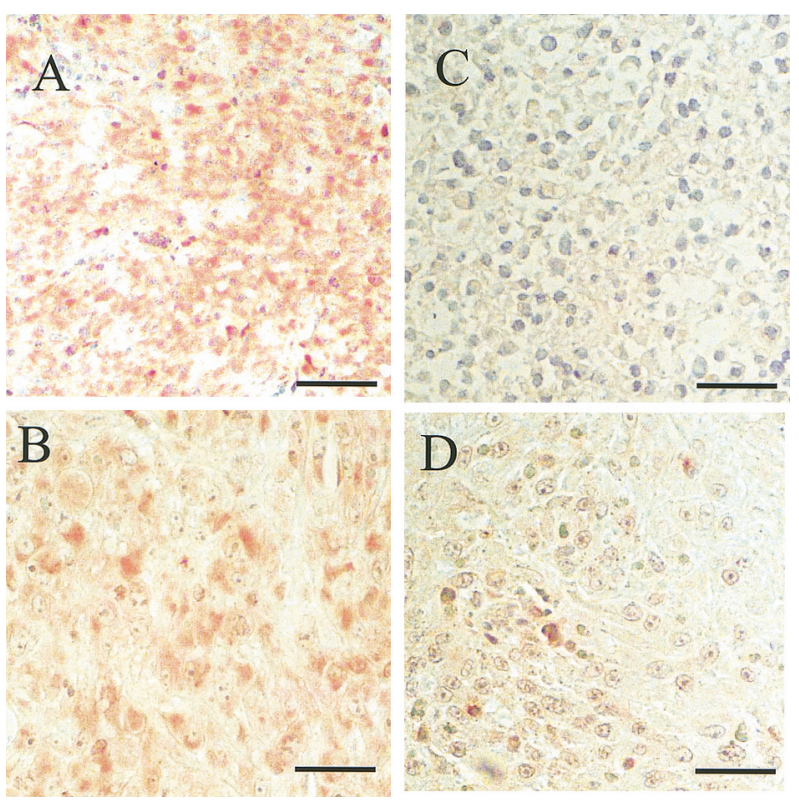

Fig. 5. Immunohistochemical detection of U-87 MG tissue VEGF localization with ACNU/VEGF antibody treatment. A. Control group. B. ACNU group. C. VEGF antibody group. D. ACNU plus VEGF antibody group. VEGF antibody alone and VEGF antibody combined with ACNU treatment dramatically decreased the VEGF protein expression of tumor cells. Bar $=50 \mathrm{~mm}$.
Table 1. Histopathologic parameters in glioma tissues treated with ACNU and VEGF antibody

\begin{tabular}{|c|c|c|c|c|}
\hline & Control & ACNU & VEGF antibody & $\begin{array}{c}\text { ACNU } \\
+ \text { VEGF } \\
\text { antibody }\end{array}$ \\
\hline MIB-I (\%) & $73.5 \pm 6.4$ & $54.4 \pm 11.4^{*}$ & $51.5 \pm 5.6^{*}$ & $7.9 \pm 2.7^{* *}$ \\
\hline $\begin{array}{l}\text { Vessel } \\
\text { density }\end{array}$ & $29.7 \pm 6.7$ & $11.5 \pm 0.7^{*}$ & $6.8 \pm 5.0^{* *}$ & $3.3 \pm 3.2^{* *}$ \\
\hline \multicolumn{5}{|c|}{$\begin{array}{l}\text { (No. of } \\
\quad \text { vessels/0.13 mm²) }\end{array}$} \\
\hline
\end{tabular}

Values are mean $\pm \mathrm{SD} .{ }^{*} \mathrm{P}<0.05,{ }^{*}{ }^{*} \mathrm{P}<0.01$ compared with control.

pared with each therapy alone with regard to the inhibition of glioma cell proliferative potential and vessel densities; in particular, the inhibitory effects of glioma cell proliferation were synergistic, not additive (one-way analysis of variance and Bonferroni test, $P<0.001)$.

\section{Combined Effect of ACNU and VEGF Antibody Treatment for U-87 MG Intracerebral Growth and Survival}

The median survival times after implantation were 34.0 \pm 1.9 days (control group), $41.5 \pm 1.9$ days (ACNU group), $45.0 \pm 4.1$ days (VEGF antibody group), and 52.8 \pm 5.5 days (ACNU plus VEGF antibody group). Combination therapy significantly prolonged U-87 MG intracerebral bearing mouse survival $(P=0.0006$, Mantel-Cox log-rank test, Fig. 6).

\section{Discussion}

Our findings document the therapeutic effect of a combination of VEGF blockade with ACNU, a cytotoxic agent commonly used in the treatment of malignant gliomas. One of the mechanisms of the combination effect is associated with an up regulation of VEGF expression with ACNU in glioma cells.

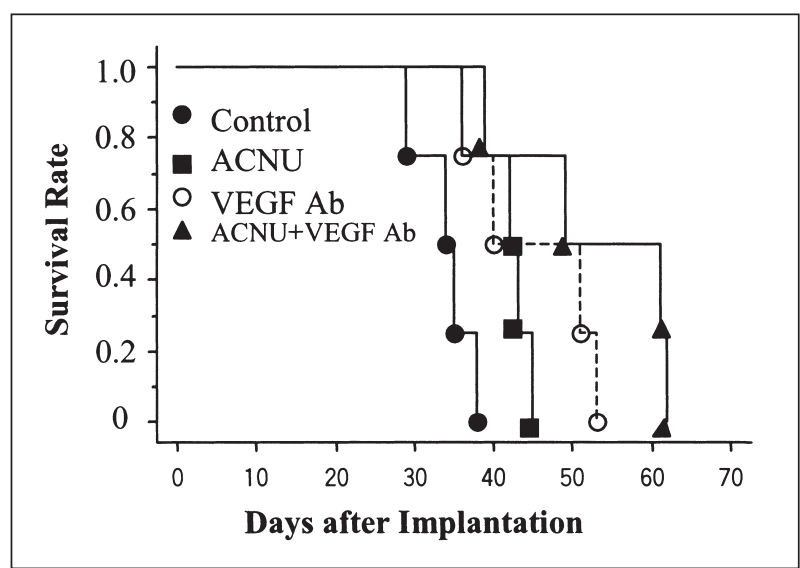

Fig. 6. Additive effect of ACNU combined with VEGF antibody treatment on U-87 MG intracerebral growth and survival. Intraperitoneal injection of ACNU at $20 \mathrm{mg} / \mathrm{kg}$ (days $4,7,10$ ) and VEGF antibody at $100 \mu \mathrm{g} /$ mouse (every 3 days, days $4-25$, total 8 times) were given. Survival rate was measured in each group $(n=4)$. 
The use of anti-VEGF antibodies has been extensively studied in preclinical in vivo models and has demonstrated an inhibition of tumor growth, including growth of gliomas (Bernsen et al., 1998; Kim et al., 1993; Yuan et al., 1996), in a dose-dependent manner (Kim et al., 1993). A phase I study with anti-VEGF, which was performed to evaluate its safety and pharmacokinetic profile in patients with relapsed and refractory malignancies, has been carried out (Gordon et al., 2001). Some patients have been observed to respond to the combination with chemotherapy. The development of combinations featuring limited exposure to adequate doses of the most active chemotherapeutic agents and a more prolonged exposure to the antiangiogenic agents has been suggested (Margolin et al., 2001).

In our study, VEGF concentrations in the antibodytreated tumor tissues increased compared with the control group. In addition, increases in total serum VEGF concentrations have been reported in VEGF treatment of solid tumors. These increases are likely a result of the decrease in VEGF clearance caused by complex formation between VEGF and VEGF antibody (Gordon et al., 2001).

The idea of combining antiangiogenic therapy with conventional therapy is not novel. TNP-470 has been shown to potentiate the effects of cyclophosphamide significantly (Teicher et al., 1994). TNP-470 has also demonstrated therapeutic synergy with ionizing radiation in glioblastoma xenografts (Lund et al., 2000); and doxorubicin, in combination with VEGF neutralizing antibody, can result in significant breast cancer regression (Borgstrom et al., 1999). Angiostatin in combination with ionizing radiation potentiates an antitumor interaction (Mauceri et al., 1998). Therapies targeting tumor angiogenesis are often effective at blocking further tumor growth and metastasis. However, small avascular tumors are often maintained in a "dormant" state. To achieve complete eradication of such dormant foci, antiangiogenic treatment may have to be combined with other treatment modalities such as conventional cytotoxic drugs (Borgstrom et al., 1999). It has been shown that the dormant colonies remaining after VEGF blockade can be further reduced by combination therapy with cyclophosphamide, which is considered to be one of the most active and widely used agents in the treatment of breast cancer (Borgstrom et al., 1999). However, the precise mechanism for the synergy and additive effects of anti-angiogenic agents with conventional therapy has not been explained. In other words, because of the decrease in efficient tumor blood flow with anti-angiogenic treatment, a combination with cytotoxic agents may be ineffective.

Synergy of ionizing radiation and anti-VEGF antibody can be explained by the following mechanisms: irradiation induction of VEGF mRNA and protein levels is mediated by Src tyrosine kinase and protein kinase $\mathrm{C}$ on the cell-surface membrane (Ando et al., 2000) and contributes to the protection of tumor blood vessels from radiation-mediated cytotoxicity and, thereby, to tumor radioresistance (Gorski et al., 1999). Estramustine combined with radiotherapy has shown a similar effect with ACNU on VEGF expression in a malignant glioma model (Johanson et al., 1999). Also, TNP-470 significantly enhances the tumor effect of ionizing radiation since acute microvascular damage after ionizing radiation is effectively prevented by concurrent TNP-470 treatment in glioblastomas (Lund et al., 2000). The synergy with angiostatin and ionizing radiation may be explained by the combined cytotoxic effects on endothelial cells, but not on tumor cells (Mauceri et al., 1998).

In the case of gliomas, ACNU, a cytotoxic agent commonly used in cancer treatment in Japan, was found to up regulate VEGF expression in vitro and in vivo. This induction of VEGF expression with ACNU was decreased by VEGF antibody. Both VEGF antibody alone and ACNU alone inhibited glioma cell proliferation in vivo, which was measured as MIB-1 positivities, but their inhibitory effects were insufficient. Also, ACNU alone $(100 \mu \mathrm{M})$ significantly inhibited endothelial cell proliferation as well as glioma cell proliferation in vitro (data not shown). ACNU treatment in vivo may have an inhibitory effect both on glioma cells and on endothelial cells. The combination of ACNU and VEGF antibody synergistically inhibited glioma cell proliferation as well as glioma angiogenesis, which was measured as vessel densities. Our data demonstrated a limited effect on i.c. glioma survival with VEGF antibody systemic treatment. Yuan et al. (1996) were able to demonstrate a significant reduction in tumor vascular permeability after anti-VEGF antibody treatment in an intracranially implanted human glioblastoma line, U-87 MG, which was the same cell line we used. Taken together, in i.c. animal models, systemic VEGF antibody treatment could reach to glioma vasculatures. However, several successful antiglioma antibody systemic treatments in animals failed to demonstrate any effect in clinical trials (reviewed in Wikstrand et al., 1999). The major obstacle with these antibody treatments is limited delivery to glioma tissues (Wikstrand et al., 1999). The mode, frequency, and timing of delivery of the antiangiogenic agents, including VEGF antibody, to the tumor will be key to their success. For future clinical trials, further studies are needed for these kinds of antiangiogenic therapies combined with chemotherapy and radiotherapy.

\section{Conclusions}

The therapeutic combination of anti-VEGF antibody and ACNU treatment for glioblastoma growth was demonstrated. ACNU, but not cisplatin and etoposide, elevated VEGF expression in glioma cells. VEGF antibody decreased ACNU-induced VEGF up regulation in addition to inhibiting glioma angiogenesis, resulting in a strong glioma growth inhibition. Glioblastoma represents an obvious candidate for future clinical testing of antiangiogenic therapy. The combination of anti-angiogenic therapy with conventional therapy is promising for future treatment of glioblastoma.

\section{Acknowledgments}

We gratefully acknowledge Yoshiko Tsukada and Makiko Miyakawa for their excellent technical assistance. 


\section{References}

Ando, S., Nojima, K., Ishihara, H., Suzuki, M., Ando, M., Majima, H., Ando, K., and Kuriyama, T. (2000) Induction by carbon-ion irradiation of the expression of vascular endothelial growth factor in lung carcinoma cells. Int. J. Radiat. Biol. 76, 1121-1127.

Asano, M., Yukita, A., Matsumoto, T., Hnatani, M., and Suzuki, H. (1998) An anti-human VEGF monoclonal antibody, MV833, that exhibits potent anti-tumor activity in vivo. Hybridoma 17, 185-190.

Asano, M., Yukita, A., and Suzuki, H. (1999) Wide spectrum of antitumor activity of a neutralizing monoclonal antibody to human vascular endothelial growth factor. Jpn. J. Cancer Res. 90, 93-100.

Bernsen, H.J.J.A., Risked, P.F.J.W., Peters, J.P.W., Bakker, H., and van der Kogel, A.J. (1998) Delayed vascular changes after antiangiogenic therapy with antivascular endothelial growth factor antibodies in human glioma xenografts in nude mice. Neurosurgery 43, 570-576.

Borgstrom, P., Gold, D.P., Hillan, K.J., and Ferrara, N. (1999) Importance of VEGF for breast cancer angiogenesis in vivo: Implications from intravital microscopy of combination treatments with an anti-VEGF neutralizing monoclonal antibody and doxorubicin. Anticancer Res. 19, 4203-4214.

Brem, S., Cotran, R., and Folkman, J. (1972) Tumor angiogenesis: A quantitative method for histologic grading. J. Natl. Cancer Inst. 48, 347-356.

Cheng, S.Y., Huang, H.J., Nagane, M., Ji, X.D., Wang, D., Shih, C.C.Y., Arap, W., Huang, C.M., and Cavenee, W.K. (1996) Suppression of glioblastoma angiogenicity and tumorigenicity by inhibition of endogenous expression of vascular endothelial growth factor. Proc. Natl. Acad. Sci. U.S.A. 93, 8502-8507.

Gordon, M.S., Margolin, K., Talpaz, M., Sledge, G.W., Jr., Holmgren, E., Benjamin, R., Stalter, S., Shak, S., and Adelman, D.C. (2001) Phase I safety and pharmacokinetic study of recombinant human anti-vascular endothelial growth factor in patients with advanced cancer. J. Clin. Oncol. 19, 843-850.

Gorski, D.H., Beckett, M.A., Jaskowiak, N.T., Calvin, D.P., Mauceri, H.J., Salloum, R.M., Seetharam, S., Koons, A., Hari, D.M., Kufe., D.W., and Weichselbaum, R.R. (1999) Blockade of the vascular endothelial growth factor stress response increases the antitumor effects of ionizing radiation. Cancer Res. 59, 3374-3378.

Jensen, R.L. (1998) Growth factor-mediated angiogenesis in the malignant progression of glial tumors: A review. Surg. Neurol. 49, 189-196.

Johansson, M., Bergenheim, A.T., Widmark, A., and Henriksson, R. (1999) Effects of radiotherapy and estramustine on the microvasculature in malignant glioma. Br. J. Cancer 80, 142-148.

Kendall, R.L., and Thomas, K.A. (1993) Inhibition of vascular endothelial growth factor activity by an endogenously encoded soluble receptor. Proc. Natl. Acad. Sci. U.S.A. 90, 10705-10709.

Kim, K.J., Li, B., Winer, J., Armanini, M., Gillett, N., Phillips, H.S., and Ferrara, N. (1993) Inhibition of vascular endothelial growth factor-induced angiogenesis suppresses tumour growth in vivo. Nature 362, 841-844.

Kirsch, M., Strasser, J., Allende, R., Bello, L., Zhang, J., and Black, P.M. (1998) Angiostatin suppresses malignant glioma growth in vivo. Cancer Res. 58, 4654-4659.

Lund, E.L., Spang-Thomsen, M., Skovgaard-Poulsen, H., and Kristjansen, P.E.G. (1998) Tumor angiogenesis: A new therapeutic target in gliomas. Acta Neurol. Scand. 97, 52-62.

Lund, E.L., Bastholm, L., and Kristjansen, P.E.G. (2000) Therapeutic synergy of TNP-470 and ionizing radiation-Effects on tumor growth, vessel morphology, and angiogenesis in human glioblastoma multiforme xenografts. Clin. Cancer Res. 6, 971-978.
Margolin, K., Gordon, M.S., Holmgren, E., Gaudreault, J., Novothy, W., Fyfe, G., Adelman, D., Stalter, S., and Breed, J. (2001) Phase Ib trial of intravenous recombinant humanized monoclonal antibody to vascular endothelial growth factor in combination with chemotherapy in patients with advanced cancer: Pharmacologic and long-term safety data. J. Clin. Oncol. 19, 851-856

Mauceri, H.J., Hanna, N.N., Beckett, M.A., Gorski, D.H., Staba, M.J., Stellato, K.A., Bigelow, K., Heimann, R., Gately, S., Dhanabal, M., Soff, G.A., Sukhatme, V.P., Kufe, D.W., and Weichselbaum, R.R. (1998) Combined effects of angiostatin and ionizing radiation in antitumour therapy. Nature (Lond.) 394, 287-291.

Millauer, B., Longhi, M.P., Plate, K.H., Shawver, L.K., Risau, W., Ullrich, A., and Strawn, L.M. (1996) Dominant-negative inhibition of Flk-1 suppresses the growth of many tumor types in vivo. Cancer Res. 56, $1615-1620$.

Reijneveld, J.C., Voest, E.E., and Taphoorn, M.J.B. (2000) Angiogenesis in malignant primary and metastatic brain tumors. J. Neurol. 247, 597-608.

Takakura, K., Abe, H., Tanaka, R., Kitamura, K., Miwa, T., Takeuchi, K., Yamamoto, S., Kageyama, N., Handa, H., Mogami, H., Nishimoto, A., Uozumi, T., Matsutani, M., and Nomura, K. (1986) Effects of ACNU and radiotherapy on malignant glioma. J. Neurosurg. 64, 53-57.

Takano, S., Yoshii, Y., and Nose, T. (1991a) Ultrastructure of glioma vesselmorphometric study for vascular permeability (Japanese). No To Shinkei 43, 49-56.

Takano, S., Yoshii, Y., and Nose, T. (1991b) Ultrastructure of glioma vesselmorphometric study for proliferative potential of endothelial cell (Japanese). No To Shinkei 43, 145-152.

Takano, S., Yoshii, Y., Kondo, S., Suzuki, H., Maruno, T., Shirai, S., and Nose, T. (1996) Concentration of vascular endothelial growth factor in the serum and tumor tissue of brain tumor patients. Cancer Res. 56, 2185-2190.

Takano, S., Tsuboi, K., Tomono, Y., Mistui, Y., and Nose, T. (2000) Tissue factor, osteopontin, avß3 integrin expression in microvasculature of gliomas associated with vascular endothelial growth factor expression. Br. J. Cancer 82, 1967-1973.

Teicher, B.A., Holden, S.A., Ara, G., Sotomayor, E.A., Huang, Z.D., Chen, Y.N., and Brem, H. (1994) Potentiation of cytotoxic cancer therapies by TNP-470 alone and with other anti-angiogenic agents. Int. J. Cancer 57, 920-925.

Wikstrand, C.J., Cokgor, I., Sampson, J.H., and Bigner, D.D. (1999) Monoclonal antibody therapy of human gliomas: Current status and future approaches. Cancer Metastasis Rev. 18, 451-464.

Yoshida, J.A., Kajita, T., Wakabayashi, T., and Sugita, K. (1994). Long-term follow-up results of 175 patients with malignant glioma: Importance of radical tumour resection and postoperative adjuvant therapy with interferon, ACNU and radiation. Acta Neurochir. (Wien) 127, 55-59.

Yuan, F., Chen, Y.I., Dellian, M., Safabakhsh, N., Ferrara, F., and Jain, R.K. (1996) Time-dependent vascular regression and permeability changes in established human tumor xenografts induced by anti-vascular endothelial growth factor/vascular permeability factor antibody. Proc. Natl. Acad. Sci. U.S.A. 93, 14765-14770.

Zagzag, D. (1995) Angiogenic growth factors in neural embryogensis and neoplasia. Am. J. Pathol. 146, 293-309. 